\title{
Discussion of citizen behavioural change using the nudge effect: a perspective based on
}

\author{
social policy interventions
}

\author{
Hiroko Oe, Bournemouth University, UK \\ hoe@bournemouth.ac.uk \\ Yasuyuki Yamaoka, The Open University Japan \\ Yamaoka-y@ouj.ac.jp
}

\begin{abstract}
Purpose

This study aims to present a communication model for promoting value co-creation between citizens and policy makers and to draw out proposals on the rationale in implementing nudge effect as well as key policy implications. The paper also revisits the close relationship between information senders and receivers (citizens) from the perspective of 'citizen behaviour change' and focusses on the nudge effect, which strengthens the communication skills of policy makers (information senders) and accelerates the behaviour change of citizens, i.e. the recipients of information. Based on the study, we propose a conceptual framework to explain the spontaneous incentive structure of citizens.
\end{abstract}

\section{Design, methodology and approach}

This study uses a conceptual discussion based on a literature review. It examines the nudge effect on citizen behaviour based on information and communications models and theories. From critical discussions of literature, it proposes an analytical model that focusses on the nudge effect put forwards in behavioural economics and takes into account the importance of measures to increase the sensitivity and empathy of the recipients of information.

\section{Findings}

We revisited the relationship between information senders and receivers from the perspective 
of citizen behavioural change and focus on the nudge effect, which strengthens the communication power of policy makers and accelerates the behavioural change of citizens, i.e. the recipients of information. According to the study, we propose a conceptual framework to explain citizens' spontaneous incentive structure. The dual perspective of policy makers and citizens should be central to the collaboration between citizens and policy makers to enhance the effectiveness of social policies, where the scope and type of value generated and the perspective of social value are essential.

\section{Originality}

Up to this point, in examinations of encouraging behavioural change in information recipients, attention has been focussed on the aspect of increasing the sender's ability to transmit information. Interventions, such as increasing the energy of the delivery, increasing the frequency and diversifying the media to make a strong impression on the receiver's consciousness, have been considered and implemented. However, this study suggests that, in addition to such efforts on the part of the sender, it is important to increase the sensitivity and affinity of the receiver to the message as preliminary preparation to receiving it.

\section{Research limitations/implications}

This paper bridges the interdisciplinary research fields of behavioural economics and social policy. It is hoped that the model proposed in this paper will be an effective discussion framework for relevant researchers and practitioners when considering human resource training and system building related to information dissemination. In addition, it is hoped the model will be an effective tool for deepening discussions on topics that help to facilitate information transfer and communication within organisations.

\section{Practical contributions}

The realisation of policy intentions within the core elements of the social policy process, such as the definition of key objectives, policy mechanisms and legislation, are central elements of 
policy formation and are said to be highly similar across countries. The framework proposed in this study is a valid resource that can be applied in other countries and can be expected to act an effective guidepost for policy makers and other stakeholders engaged in social policy.

\section{Introduction}

\subsection{Study background}

This paper examines the key elements of communication that influence how information receivers change their behaviour. Based on a discussion developed from the 'throwing reach model', a model of information propagation and the relationship between information sender and receiver, we discuss the process by which the intentions of the information sender are communicated to the receiver and evoke an interactive response. This is further interwoven with a discussion of the nudge effect, a finding from behavioural economics. The aim of this research is to further develop the throwing reach model to focus on aspects related to the cognition and awareness of the receiver as well as to propose a new research model adapted to the information transmission analysis.

1.2 Study rationale, research gap and research questions

Recently, the nudge effect has attracted significant interest in the operation of social public policy (John, 2013; 2018; Sunstein, 2020). The nudge effect has also attracted interest as a marketing technique. Research into the modelling and empirical analysis of market consumers' attitudes and behaviours with the goal of understanding the mechanisms in play and how these can be applied to corporate marketing strategies has promoted ecological marketing as a part of marketing communications and brand strategies. This trend is based on the application of nudges to induce behavioural change among consumers, which also contributes to the United Nations Sustainable Development Goal (SDG) 12 ('Ensure sustainable consumption and 
production patterns'). It is now a well-known fact that nudges are also used in activities that contribute to social issues, such as the promotion of environmentally friendly products (de Ridder et al., 2021; Mélon, 2020). An important point here is the element of connecting with consumers' consumption styles and lifestyles, which has proven to be effective in encouraging the introduction of new products with a low environmental impact.

However, there is a gap in the operation of such public policies, specifically, in the way in which information is disseminated to consumers, upon which we focus herein (Becchetti et al., 2020; Roozen et al., 2021). Let us consider the case of encouraging consumers to buy ecofriendly products or to pay attention to products with low environmental impact. No one would argue with a message that encourages such socially acceptable behaviour (Entwistle, 2021; Kristal \& Whillans, 2020). However, there has been no debate on how this message can be communicated in such a way that the consumer who receives it is able to digest the information, understand it, empathise with it and take it to the level of behavioural change.

Three key research questions emerged from this situation and debate, as follows:

RQ 1: What are the key mechanisms in promoting citizen behaviour change through communication between citizens and social policy makers?

RQ2: Is it possible to promote behavioural change through the nudge effect, and, if so, what points should social policy makers consider and act upon?

RQ3: What should the conceptual framework to explain the voluntary incentive structure of citizens through the nudge effect be?

\section{Literature review}

2.1 Discussion of an information propagation model

\subsubsection{Modelling based on the concentric circle model}

The concentric circle model, applied currently in urban development studies and economic 
geography, is an analytical framework proposed by Burgess (1923) as a conceptual model of urban land use. He suggested that a city could form concentric circles around a single centre, while comprising different areas, such as a central business district (CBD), low-income residential area and an uptown. Originally, this model was based on the hypothesis that the value of land declines as it moves away from the centre. The model can be understood as implicating that the amount of information transmitted decays as the distance increases (Yamaoka \& Oe, 2021a).

Through the articulation of this famous concentric circle theory, Burgess can be credited with opening up a new horizon in economic geography by making the spatial patterns of Chicago's urban growth and the concerns of the Chicago School of urban sociology accessible. Particular attention should be paid to this concentric circle model, as it not only supports static analysis but also provides a perspective on the dynamic evolution of urban development. Based on this, actionable implications could be developed in interdisciplinary fields of academia, including communications management.

In terms of the dynamics of urban expansion, Burgess discusses the following:

(1) Residential mobility as a spatial process of social mobility - the reality of moving outwards and inwards. He also discussed the process of city expansion.

(2) The expansion process of the city itself, according to which the concentric circles themselves tend to expand: In this case, the residential area is transformed from a workers' residential area into a central business district through the transition zone. He discusses this phenomenon as a change of community by 'invasion' and 'succession'.

(3) The ethnic mosaic of migrants and the urban division of labour: Burgess focusses on the process of transformation from a 'mosaic' of immigrant settlements to a system of division of labour dominated by a central business district. Burgess discusses the process of centralisation, that is, the domination of each district by a central business district, and at the same time 
decentralisation, that is, the expansion of the city and the spatial dispersion of the various elements of urban function.

The above considerations suggest that this model may be a useful tool for examining how the transmission of information can be conveyed, with the strength of the message weakening the further it moves from the centre, changing how the recipients of the information react to it. The basic proposition that land prices fall as one moves further away from the city centre can be discussed not only in terms of the decay of information but also in the context of the changes in the behaviour of information receivers brought about by shifts in the transmission and dissemination of information. In this way, it can be expected to contribute to the extraction of issues that cannot be overlooked and used to improve the effects of public policy through considering changes in the behaviour of information receivers via focus on the nudge effect, which is the main focus of this research.

Figure 1 illustrates our proposed concept based on Burgess' model. Here, the curve indicates the value of the land (= information), which decreases as the recipients move away from the central point of information dissemination.

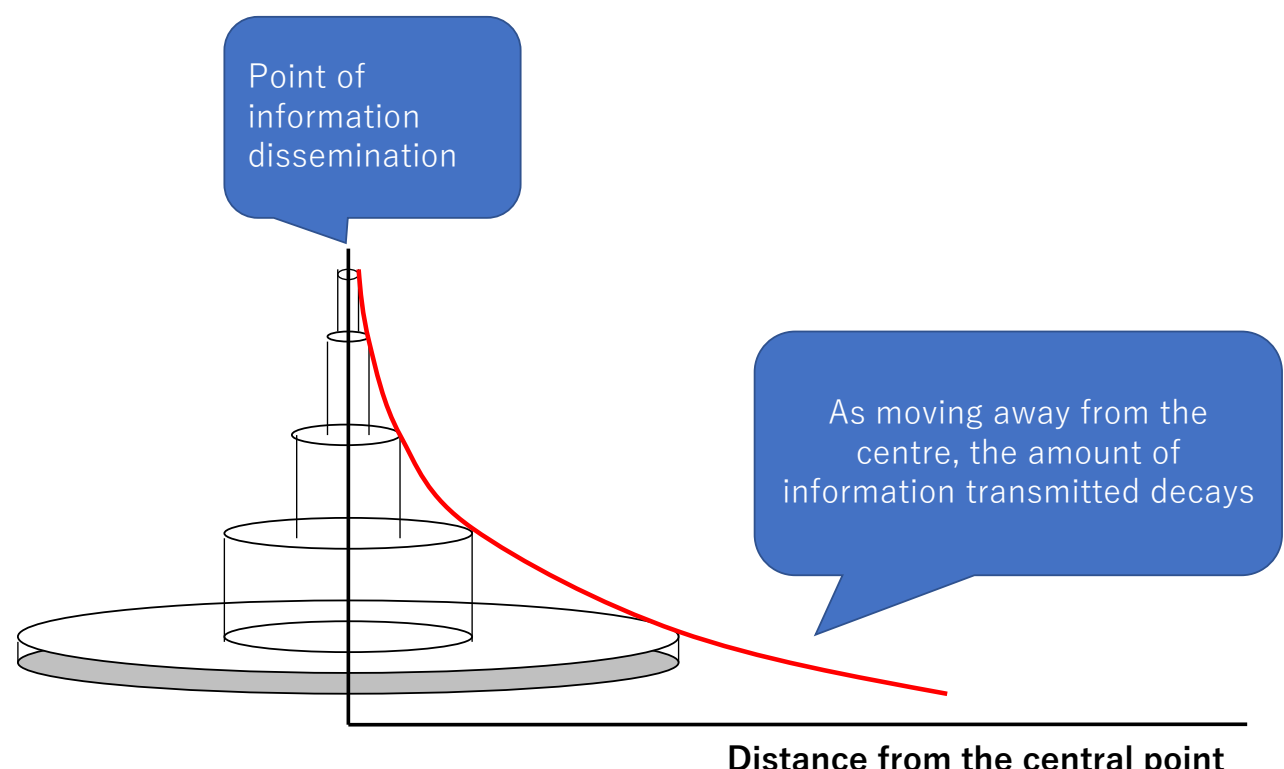

Figure 1. Information decay model based on Burgess (1923). 
This model indicates that the amount of information capable of being transmitted to a certain point is attenuated as one moves further away from the point of origin. It also provides useful insights into the subject of our present study: information propagation and behaviour change among recipients. In other words, in line with Burgess' arguments regarding the land value model, in the usual course of information propagation, physical distance (i.e., distance away from the information transmission point) is a metaphor for the receiver's attitude and affinity to the message as well as for their willingness to listen to, digest and interpret the received information. The presence or absence of this mindset represents the first barrier to successful information dissemination. The results of information dissemination can only be assessed if we can confirm the sequence of events that led the listener to have a certain level of sympathy and resonance with the information received along with willingness to respond to it by changing their own behaviour.

\subsubsection{Behaviour change to realise policy aim}

To operationalise this model, Yamaoka and Oe (2021a) projected concentric circles of information propagation onto a two-dimensional graph, visually depicting the fact that information does not reach recipients beyond a certain distance from the point of origin. They call this the 'threshold' of information, arguing that by increasing this threshold, recipients will be better able to empathise with information and have it influence their behaviour. The purpose of communication, they argue, is that the receiver be affected by the information, i.e., that the propagation of the information leads to a concrete change in behaviour on the part of the receiver. Fukada (1998), a leading authority on communication theory, also stresses that communication should be discussed as a two-way information exchange, taking into account the aspects of communication that affect the relationship between an organisation and the people gathered 
there. In line with the discussion, El-Deeb et al. (2020) emphasise the importance of investigating the determinants of intentions regarding social adaptation and demonstrate that subjective norms and perceived behavioural control, which the theory of planned behaviour focus on, evoke pro-environmental intentions and thus pro-environmental behaviour. In other words, in order to investigate the intention-inducing effects of public sector interventions, which they argue define subjective norms, it is significant to focus on the communication between policy makers as information transmitters and citizens as information receivers.

If the energy of the information emanating from the central location is constant, the condition for arousing the receiver's sympathy and evoking a change in the receiver's behaviour is that the receiver be within a certain distance (Nagayama, 2005). In other words, as suggested by the Burgess land price model, the greater the distance from the metaphorical city centre, the lower the 'land price' (amount of information transmitted). Accordingly, if our goal is to activate far-away recipients, we need to transmit a large amount of information energy and devise ways of amplifying the amount of information that reaches these information receivers. Similarly, in the context of social policy interventions, Bongomin et al. (2020) examine the effectiveness of social networking and communication on realising a policy aims and objectives. The authors found that financial literacy has a direct significant and positive effect on the financial inclusion of the poor by microfinance banks in developing countries. In the process, the authors also discovered that active information exchange and communication over social networks can significantly mediate the financial inclusion of the poor through microfinance banking in developing countries.

If the receiver's sensitivity is high - or, alternatively, if the receiver's mindset is such that he or she is interested in the sender's information or has the intention to listen to it and exhibits a high affinity to it - communication will be smooth and effective, and the degree of change in the receiver's behaviour can be expected to be relatively high. It is also an important 
point to assume that the receiver's sensitivity to the message is related to some similarity with the sender (homophily).

The homophily-heterophily argument proposed by Rogers and Bhowmik (1970) is the basis for the study of the notion of relationship in communication research and has been used to explain the relationship between public policy and public sector messages communicated to citizens and the expectation of behavioural change in order to enhance their effectiveness. In other words, it is used to explain the relationship between citizens' expectations of behaviour change. This idea, proposed in 1970, that citizens' trust in and familiarity with the public sector can be increased in preparation to improve the effectiveness of policies remains an important guiding principle in social policy research 50 years later.

\subsection{Factors leading to behavioural change in information recipients}

\subsubsection{The nudge effect in behavioural change}

In the UK, the Cameron government adopted a policy based on nudge theory in 2010 and launched the Nudge Unit (Behavioural Insights Team), which created a successful model for civic education and social change as represented by tax issues and road accident prevention. Since then, civic education policies incorporating nudge theory have been developed in many countries, including France, Australia and Brazil.

Nudging is a method of encouraging people to carry out actions that are desirable for society as a whole without coercion. Such policy methods include (1) financial methods, which use financial incentives; (2) regulatory methods, which use laws to regulate actions; and (3) informational methods, which are based on the provision of information. As a discipline, nudging is becoming established as a behavioural science method in the field of policy science. Moreover, it can be distinguished from informational methods in that it adds psychological and behavioural features.

One way in which the nudge effect has been used to change people's behaviour is the 
application of gamification in education. Since the 2000s, when gamification research was known as serious game research, the effects of games beyond entertainment have attracted increasing interest, especially in the US. The experience of playing a game can be used to optimise the behaviour of, for example, a manager in a game scenario or a policymaker in the public sector who aims to solve socioeconomic problems. In Japan, a team from the University of Tokyo has been working on the development of an educational module for the social sciences (Prensky, 2006). Another team from the University of Tokyo has confirmed the effectiveness of games in history education (Sakamoto, 2013), and empirical studies of game use to stimulate pro-environmental behaviour are accumulating (Takemoto \& Oe, 2021). What these studies have in common is a focus on the fact that some unspecified factor in the game triggers the subjects to take action on their own, which is consistent with the argument suggested by nudge theory. In fact, recent gamification research suggests that gamification has a strong affinity with nudge theory in terms of increasing motivation and stimulating interest (Douglas \& Brauer, 2021). Figure 2 presents the factors leading to behavioural change based on three steps: information receivers' intentions and awareness, the process of behavioural change and triggers and reactions that produce nudge effects.

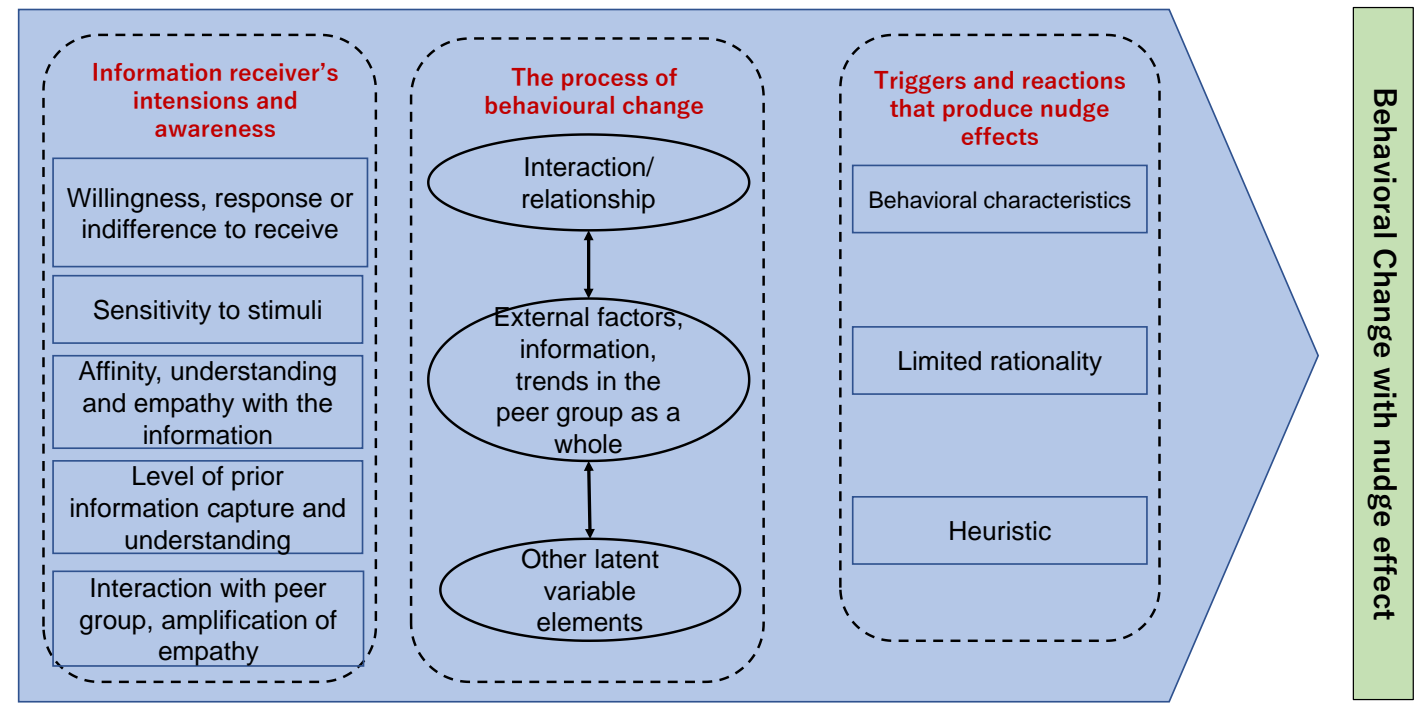

Figure 2. Conceptual framework leading to nudge-effected behavioural change (source: authors' collection) 
At present, empirical research findings in this area are gradually accumulating, and there are high hopes for the potential of policies based on nudge theory and expectations of behaviour change mechanisms. However, as noted at the beginning of this paper, there is almost no extant research focusing on the role of information dissemination and communication in the process of promoting behaviour change.

\subsubsection{Advance preparation for and catalytic effect of the nudge effect}

This study proposes a new perspective on the nudge effect taught by behavioural economics, paying attention to the information sensitivity and empathy on the part of the receiver in achieving effective communication between the sender and receiver of a message. The aim is to extract factors effective in promoting behavioural change on the part of the recipient of information. For example, consider the problem of looking after elderly people living alone in the community. Policies that have focussed on psychological factors without financial burden, with the intention of introducing the nudge effect specifically into public interventions, have had various effects (Hansen \& Jespersen, 2013). The strategy of achieving policy objectives by working on the psychology of the general public and inducing behavioural changes, such as by promoting recycling to achieve a sustainable circular economy, discouraging littering and beautifying street corners or talking to the elderly to make sure they are safe, is attracting attention as a new style of public intervention (Banerjee \& John, 2020).

Oe (2007) argues that the communication of tacit knowledge to induce innovative behaviour into recipients is a key element in the interaction between high-need users (information seekers) and suppliers (sticky information holders). Oe (2007) further argues that face-to-face communication is effective, especially when the information is related to a specific group of people or geographical area (von Hippel, 1994). Assuming here that the recipient side adheres 
to the surrounding cluster members and community, it is important to extract the adherent information and use it for higher-level innovation. This requires not only energy on the part of the sender but also a willingness on the part of the receiver to create new value (Nagayama, 2005). Oe (2007) also argues that the trust fostered in the situation is essential to facilitate the exchange of information between the sender and the receiver. Further, in order for the exchange of information backed by trust to trigger a chain of behavioural change (Ansell et al., 2020), it is important to have a third presence that exerts a catalytic function, such as through public intervention, clear messages or external support (Parker et al., 2021).

These studies stress the importance of close interaction, trust and empathy between the sender and receiver of information as well as that of a positive attitude and mindset on the part of the receiver. This approach and idea have been supported by Dorigatti et al. (2020), who proposed a new perspective based on a hybrid relationship. Rather than discussing the public and private sectors as being in opposition to each other, they discuss a pathway for combining them and confirming their legitimacy. In particular, they examine three areas of social and educational services - care for the elderly, early childhood education and kindergarten education - and discuss the effects of externalisation as well as the possibility of providing a different types of mixed welfare in order to implement the required social policy objectives. In doing so, they emphasise the importance of building a system that supports information sharing and collaboration between the parties involved in the implementation of outsourcing public services (such as local authorities), which is being promoted in developed countries.

It should be noted that in situations in which the group or social environment to which the recipient belongs sympathises or resonates with the sender's information and expects a change in behaviour, this change in behaviour may be either stimulated (a positive effect that accelerates) or hindered (an effect that works negatively). Taking into account the concept of the 'imitation effect' or 'contagion effect' may be a useful guide. The contagion effect has 
already been discussed by a number of experts, including with regard to the impact of emotions on communication (Hasford et al., 2015), the effect of individuals becoming a crowd (Le Bon, 2007) and the contagion effect of networks (Sampson, 2012). These discussions contain issues that should be referred to in the context of achieving desirable behavioural changes through the nudge effect.

\section{Methodology}

\subsection{Approach}

This study uses a conceptual discussion approach based on a literature review (Wydra, 2020). It examines the nudge effect on citizen behavioural changes based on information and communication models and theories. Based on critical discussions of relevant literature, it develops an analytical model that focusses on the nudge effect proposed in behavioural economics and takes into account the importance of measures to increase the sensitivity and empathy of the recipients of information.

This article also aims to identify the main factors that cannot be overlooked in stimulating citizens to change their behaviour in accordance with the intentions of policy makers and the aims and directions of social policy, with the objective of developing an analytical model for this purpose. We also pay attention to the use of the nudge effect (from behavioural economics), which has recently attracted a great amount of attention in the field of public and social policy, in bringing about behavioural change in citizens.

The realisation of policy interventions in the social policy process, which includes the definition of the major goals, policy mechanisms and legislation, are all central elements of policy formation and are very similar across countries (Bagattolli \& Brandão, 2021), even if they differ to some extent within each national context. Therefore, the framework proposed by this study (a nudge model to stimulate behavioural change in citizens) is likely to be a valid 
resource that can be applied in other countries. This study thus uses this research aim to propose a generalisable analytical model, relying on the main arguments in the existing literature and integrating and modelling them.

\subsection{Data analysis and model development}

Using NVivo 12, a descriptive analysis was conducted to develop key topics from the literature. The thematic analysis of the secondary data was then conducted via desk research. With the help of a computer-mediated analysis software, the extraction of categories and codes for the main topics was carried out smoothly and efficiently. During this process, we redefined the close relationship between information senders and receivers (citizens) as 'citizen behavioural change' and focussed on the aim of developing a conceptual framework to explain the spontaneous behavioural change of senders and receivers (citizens). We also focus on the nudge effect, which accelerates behavioural change on the receiving side and strengthens the sending power of senders. The overall aim was to develop a conceptual framework to explain the spontaneous incentive structures of citizens. This dualistic perspective should be at the heart of any collaboration to realise the pitfalls and objectives of social policy, where the scope and type of value generated as well as the social value perspectives are essential.

After obtaining an overall picture of the key terms mentioned by the interviewees based on the NVivo analysis (DiCicco, Bloom \& Crabtree, 2006), we developed a number of wordto-word relationship maps. As one of the steps for coding and theorisation, the Steps for Coding and Theorisation (SCAT) analysis method was used for supplementary analysis (Otani, 2007). Based on this dual approach, we extracted key terms and phrases and presented them as relational word maps reflecting the insights, thoughts and perspectives of the interviewees in depth. As a result of the analytical procedure, the following combinations of words and subjects were developed for further discussions. 
4. A proposed information nudge model

4.1 Focus on the receivers' readiness and sympathy

We will now sum up the discussion thus far and then proceed to discuss our proposal. The first condition for evoking behavioural change in information receivers is, as Nagayama (2005) argues, to place the receiver at a certain distance, i.e. to reduce the distance divergence, in order to effectively transmit the information. Proximity makes it possible for the sender and receiver to communicate face to face in an intimate and trusting manner. Yamaoka and Oe (2021a) accordingly proposed the throwing reach model (Figure 3) as a framework to amplify the sender's energy (e.g. loudness of voice and frequency of repetition) and evoke behavioural change. This model is based on the idea of requesting that the sender make an effort to improve their ability to transmit information.

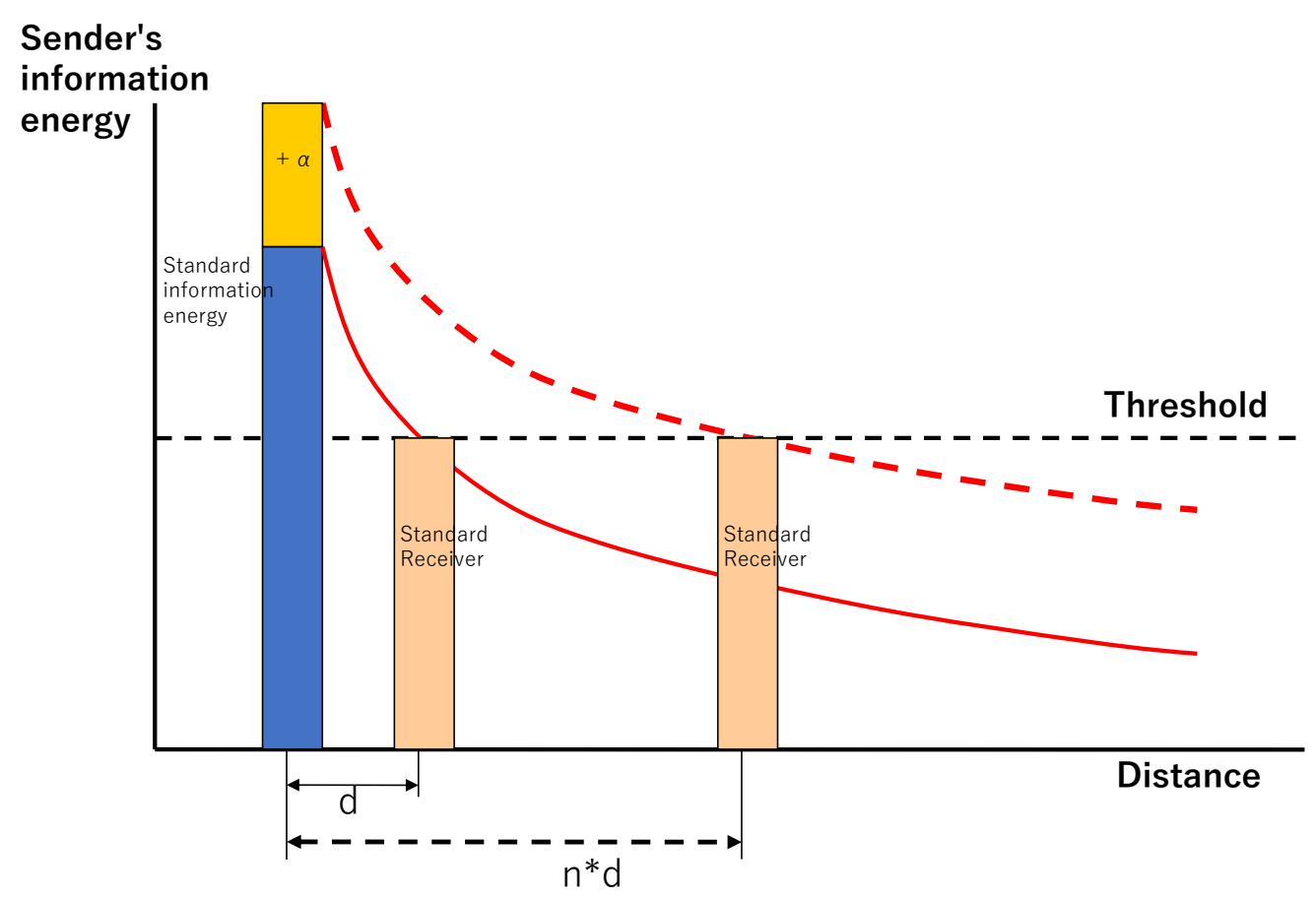

Figure 3. Throwing reach model (Yamaoka \& Oe, 2021a). 
However, in the context of actual communication, it may not always be practical to amplify the power of information dissemination by decreasing the physical distance or increasing the frequency, that is, to focus only on the sender's responsibility. Therefore, in addition to the measures suggested by the throwing reach model (such as decreasing the physical distance or increasing the frequency and volume of information transmission), a more holistic approach and modelisation based on mutual interactions between senders and recipients of information would be useful (Healey \& Leatham, 2021).

As has been repeatedly stressed above, to prompt a change in the receiver's behaviour through information propagation in the first place, methods have been proposed that focus on how to transmit with a large amount of energy and how to improve the absorption of the transmitted information (the sponge effect) by increasing the preparedness, sensitivity and affinity on the receiver's side. Considering this point, we propose necessary elements and guidelines to increase the sponge effect on the information recipient side, as shown in Figure 4.

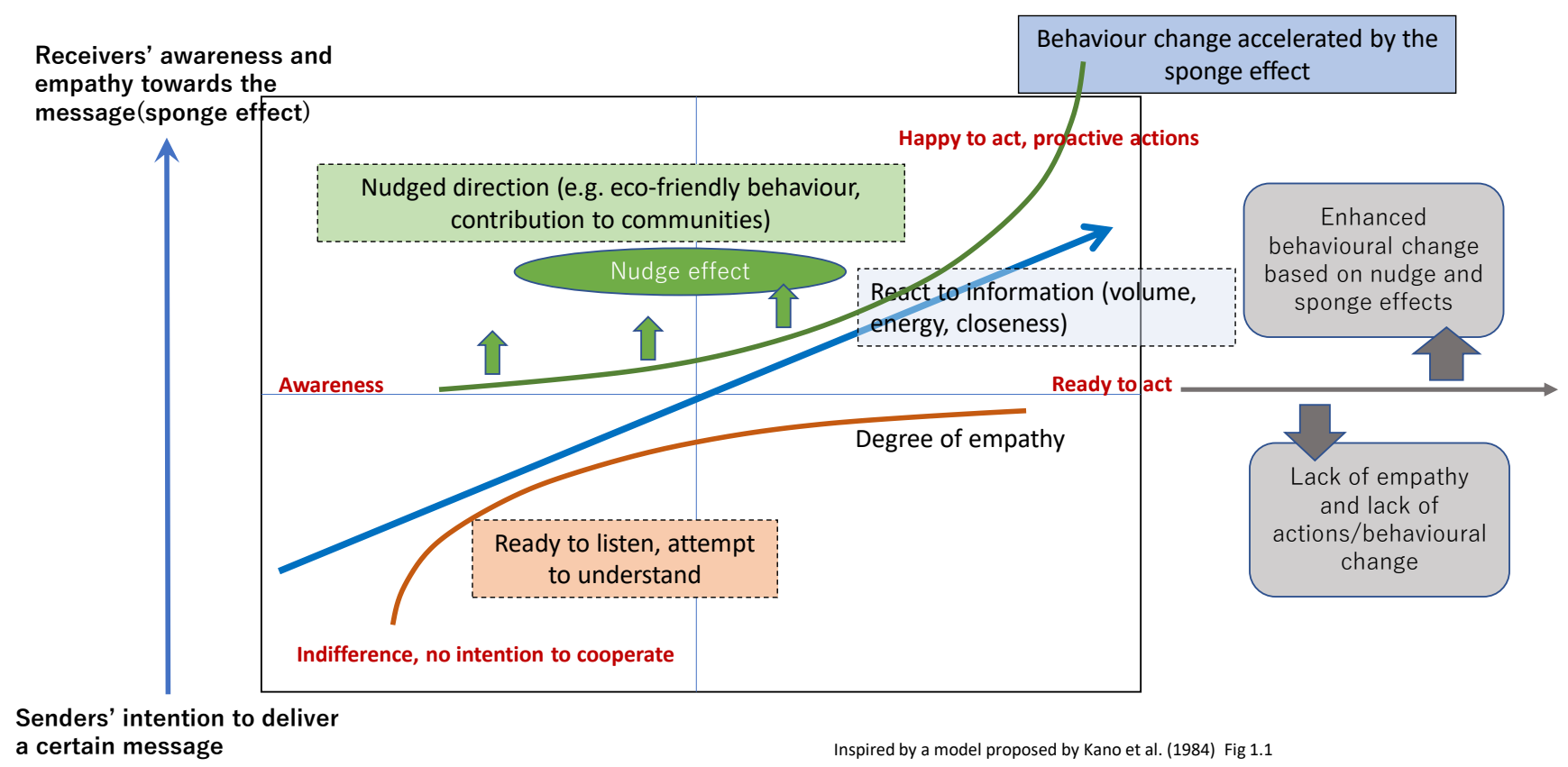

Figure 4. Nudge effect urging behavioural change based on sponge effect. 


\subsection{Discussion}

The core concept of the throwing reach model involves attempting to communicate information to the receiver more effectively by reducing the distance divergence. In addition to its status as a proxy variable for measuring intimacy, trust and interaction, Yamaoka and Oe (2021b), the inventors of the throwing reach model, have suggested that distance can amplify the energy of the sender (e.g. through loudness of voice and frequency of repetition) and increase the likelihood that the sender will be able to communicate with the receiver and consequently evoke behavioural change. In other words, the model shown in Figure 3 is based on the idea that the sender is required to make efforts to increase the power of information transmission.

However, in actual communication, it may be impractical to focus only on the sender's responsibility, that is, on amplifying the power of information dissemination by increasing the physical distance or the information dissemination frequency. Therefore, in addition to the measures suggested by the throwing reach model, which suggests that the energy of the sender should be amplified and the propagation to the receiver should be increased, this study will propose a model focusing on the nudge effect to facilitate behavioural change (Figure 4).

Given the difficulty of adopting financial inducement policies due to fiscal constraints, uncertainties caused by the coronavirus pandemic and other factors including the need to enhance behaviour based on collaborative decision-making, schemes designed to inspire behavioural change in recipients through the dissemination of information will be of increasing interest in the future. In this context, bringing together the interdisciplinary knowledge of the social sciences and presenting practical suggestions represents a significant contribution.

In the past, significant attention has been paid to how to transmit information with high energy and how to transmit it to the receiver. At the same time, the debate over the nudge effect proposed by the throwing reach model and behavioural economics suggests that it is important 
to enhance the sponge effect to improve absorption of the transmitted information by increasing the preparedness, reception sensitivity and affinity of the receiver. The proposed model can therefore be used to develop more actionable implications for policymakers and practitioners, taking into account both senders and receivers' attitudes and perceptions and using the elements and guidelines necessary to enhance the sponge effect on the part of information receivers.

As discussed, we reconsider the close relationship between information senders and receivers (citizens) from the perspective of citizen behavioural change and focus on the nudge effect, which strengthens the transmission power of policy makers (information senders) and accelerates behavioural change on the part of citizens, i.e. information receivers. In this study, we propose a conceptual framework to explain the spontaneous incentive structure of citizens, similar to the one suggested by Reijula and Hertwig (2020). The dual perspective of policy makers and citizens should be central to the collaboration between citizens, policies and bureaus to enhance the effectiveness of social policies, where the scope and type of value generated and the social value are essential (De Silva et al., 2021).

This study aimed to respond to three key research questions and to present a communication model for facilitating the co-creation of value between citizens and policy-makers, and it succeeds in eliciting suggestions on the rationale for public interventions to support co-creation and on key aspects of their policy implications. The outcome of this study is to emphasise that in order to solve and support social challenges through the co-creation of policy values via social policy, it is necessary to integrate tangible and intangible inputs into policy design, define appropriate operational models and address mechanisms to strengthen specific capacities and practices (Ewert \& Thomann, 2021). At the same time, such knowledge can help politicians to communicate effectively with citizens. However, not all politicians and advocates are good, well-meaning people (Hansen \& Jespersen, 2013). If the knowledge discussed here is deliberately and arbitrarily misused, it could be a means of manipulating citizens by guiding partisan 
interests and allowing those in power to run amok. Therefore, it goes without saying that a communication process of this nature needs to be managed and controlled in a balanced and appropriate manner and from a fair and just perspective.

Although this study relied solely on text mining of existing secondary data and did not take an empirical approach to primary data, it is important to recognise the prominence of eliminating common biases in analytical frameworks and methods in the design of scientific research. Further, it will be necessary to pay attention to the method of cross-sectional design when conducting future studies based on primary data (Spector, 2019; Williams \& McGonagle, 2016).In addition, it will be essential to design studies that take into account common methods variance (Fuller et al., 2016; Simmering et al., 2015).

\section{Conclusion}

\subsection{Overall contribution}

\subsubsection{Theoretical implications}

The discussion here is relevant to very topical issues, including the emergence of urgent needs that require the efforts and involvement of all, given the situation of the global pandemic and climate change. This conceptual study has deepened the existing debate by proposing an analytical model to show which methods effectively convey information to information recipients accurately and over long distances in a way that inspires them to change their behaviour. This paper has provided a framework for a new debate based on the throwing reach model and refers to the nudge effect as regards the degree of readiness and empathy among information receivers.

In order to extend the interaction between the sender and receiver, the sender's communicative energy needs to be amplified (such as through loudness of voice, frequency of repetition, etc.). In other words, the sender is responsible for increasing his or her 
communicative power in order to bring about behavioural change in the receiver. Much attention has accordingly been paid to the question of how high-energy information might be sent and conveyed to the receiver in order to promote behavioural change.

At the same time, in the debate on the nudge effect proposed in behavioural economics, it has been noted that it is important to increase the sponge effect, i.e. the degree to which transmitted information is absorbed, by increasing the readiness, reception sensitivity and affinity to the message on the part of receivers, as a first step in stimulating behavioural change. In this study, the nudge effect was investigated, suggesting it is important to develop a framework for enhancing the sponge effect.

We have observed that much attention has been paid to how to amplify communication. In contrast to this, it has been emphasised the readiness and sensitivity of the receiver are important, and both these aspects of interaction determine the degree of behaviour change in the receiver. However, the content of the message should also be considered, as it may influence the degree of behavioural change in the recipient. Therefore, the possibility that the content of the transmitted information may also have an important impact should be further investigated when discussing communication and behaviour change (i.e. of the many influencing factors, content could be the most important and may or may not attract more recipients). Accordingly, one of the most significant theoretical contributions of this study is the provision of critical discussion points within this field of study.

\subsubsection{Managerial implications}

We now present some of the practical implications of the study. We already highlighted the social implications of this research and how the gap in existing research on the topic should be filled. In particular, the proposed model should be used as a practical guidepost for practising policy makers and relevant stakeholders. The new model presented as in Figure 5 can 
also be an effective guideline for policy makers and entrepreneurs when they want to guide citizens and consumers in a certain direction. For example, it could be used as a framework that suggests the importance of efforts to increase the sensitivity of information receivers to stimulate behavioural change, in addition to efforts to increase the propagation power of information senders. In actual communication, it may be impractical to focus only on the sender's responsibility, i.e. the act of amplifying the power of information dissemination by increasing the physical distance or the frequency of information dissemination. Therefore, in addition to the measures suggested by the throwing reach model, which suggests that the sending energy of the sender should be amplified and the propagation to the receiver should be increased, this study proposes a model focusing on the nudge effect to facilitate behavioural change on the part of the receiver, which could represent a useful guidepost for policy makers and relevant practitioners.

\subsection{Limitations and future research directions}

This study is characterised by a focus on the improvement of sensitivity to information facilitated by the nudge effect suggested by behavioural economics along with the improvement of readiness for behavioural change as factors to stimulate behavioural change in information receivers. The results of this research are only conceptual, and further research will be required to develop actionable implications.

The most distinctive feature of this study is that it focusses on the improvement of sensitivity to information and readiness for behavioural change through the nudge effect suggested by behavioural economics as factors that promote behaviour change in recipients. However, the authors are also aware that the results of this study are only conceptual and that further research is needed to determine their practical implications. As mentioned earlier, exploring the problems of citizens' communication requires a participatory methodology that allows us to 
understand and clarify the meanings contained in the findings. Therefore, it is necessary to collect primary data on citizens' attitudes and perceptions and to analyse them in detail in order to properly understand the actual problems and to make more concrete proposals.

In the context of actual communication, it may not be realistic to focus solely on the responsibility of the sender, i.e. the act of amplifying the power of information transmission by increasing the physical distance or the frequency of information transmission. Therefore, in addition to the measures suggested by the throwing reach model, which suggests amplifying the sender's transmission energy and increasing its propagation to the receiver, we expect that a model that focuses on the nudge effect and encourages the receiver to change his or her behaviour will be a useful guidepost for further communications research.

This study is still at the pilot level, and one of its important limitations is the need for further elaboration of the arguments, further comparison with the models proposed by existing studies and discussion on how to evaluate and improve the model proposed in this study. We have discussed our interpretation that without empathy or resonance with the information received by the receiver, the receiver's understanding of the information will not progress, and behavioural change that incorporates the sender's intentions is unlikely to occur. Measuring the receiver's empathy or resonance with the information and examining its impact on behavioural change are issues for future research.

As a next step, among the implementation of other qualitative methods, we plan to carry out semi-structured interviews with policy makers and citizens involved in social policy to collect primary data and to use text mining as a starting point for understanding the current situation. Then, by testing and improving the model proposed in this paper, we believe that it will be possible to make more concrete and workable policy recommendations. The methodology used in this study is supported by the literature, the secondary data was collected by literature review, and the textual data was analysed using NVivo and SCAT. This was followed by a 
discussion.

Overall, the output of this study is the proposal of a framework and model for discussion at the pilot level, but we are fully aware that in order to explore the issue of citizen communication, a participatory methodology that allows us to understand and clarify the meaning contained in the findings is required. The contribution of this research at the present stage would then be enhanced to the level of adequately describing the actual problem. In the next stage of the research, plans are in place to collect primary data on citizens' attitudes and behaviours and to carry out an in-depth analysis to adequately understand the real problem and propose more concrete suggestions.

\section{References}

Ansell, C., Doberstein, C., Henderson, H., Siddiki, S. \& Hart, P. (2020). Understanding inclusion in collaborative governance: a mixed methods approach. Policy and society, 39(4), $570-591$.

Bagattolli, C. \& Brandão, T. (2021). Contesting the Mainstream Narrative? A Conceptual Discussion on the Politics of Science, Technology, and Innovation from the Periphery. Journal of Scientometric Research, 10(1s), s5-s20.

Banerjee, S. \& John, P. (2020). Nudge plus: incorporating reflection into behavioral public policy. Behavioural Public Policy, 1-16.

Becchetti, L., Salustri, F. \& Scaramozzino, P. (2020). Nudging and corporate environmental responsibility: A natural field experiment. Food Policy, 97, 101951.

Bongomin, G. O. C., Ntayi, J. M. \& Malinga, C. A. (2020). Analyzing the relationship between financial literacy and financial inclusion by microfinance banks in developing countries: social network theoretical approach. International Journal of Sociology and Social Policy, 
$40(11 / 12), 1257-1277$.

Burgess, E. W. (1923). The growth of the city: An introduction to a research project. Publication of the American Sociological Society, 21, 178-184.

de Ridder, D., Kroese, F. \& van Gestel, L. (2021). Nudgeability: Mapping conditions of susceptibility to nudge influence. Perspectives on Psychological Science, 1745691621995183.

De Silva, M., Gokhberg, L., Meissner, D. \& Russo, M. (2021). Addressing societal challenges through the simultaneous generation of social and business values: A conceptual framework for science-based co-creation. Technovation, 104, 102268.

DiCicco-Bloom, B. \& Crabtree, B.F.(2006). The qualitative research interviews. Medical education, 40(4), 314-321.

Dorigatti, L., Mori, A. \& Neri, S. (2020). Public, private or hybrid? Providing care services under austerity: the case of Italy. International Journal of Sociology and Social Policy, 40 (11/12), 1279-1300.

Douglas, B. D., \& Brauer, M. (2021). Gamification to Prevent Climate Change: A Review of Games and Apps for Sustainability. Current Opinion in Psychology, 42, 89-94.

El-Deeb, S., Correia, M. \& Richter, C. (2020). A fuzzy set analysis of the determinants of intention to adapt and pro-environmental behaviour. International Journal of Sociology and Social Policy, 41 (7/8), 786-804.

Entwistle, T. (2021). Why nudge sometimes fails: fatalism and the problem of behaviour change. Policy \& Politics, 49(1), 87-103.

Ewert, B., Loer, K. \& Thomann, E. (2021). Beyond nudge: advancing the state-of-the-art of behavioural public policy and administration. Policy \& Politics, 49(1), 3-23.

Fukada, H. (1998). Interpersonal communication. Kyoto: Kitaoji Shobou.

Fuller, C. M., Simmering, M. J., Atnic, G., Atinc, Y. \& Babin, B. J. (2016). Common Methods Variance Detection in Business Research. Journal of Business Research, 69(8), 3192-3198. 
Hansen, P. G. \& Jespersen, A. M. (2013). Nudge and the manipulation of choice: A framework for the responsible use of the nudge approach to behaviour change in public policy. European Journal of Risk Regulation, 4(1), 3-28.

Hasford, J., Hardesty, D. M. \& Kidwell, B. (2015). More than a feeling: Emotional contagion effects in persuasive communication. Journal of Marketing Research, 52(6), 836-847.

Healey, R. \& Leatham, C. (2021). How to persuade and influence people: the art of effective geographical debate. Journal of Geography in Higher Education, 1-11.

John, P. (2018). How far to nudge?: Assessing behavioural public policy. Edward Elgar Publishing.

John, P. (2013). Experimentation, behaviour change and public policy. The Political Quarterly, 84(2), 238-246.

Kristal, A. S. \& Whillans, A. V. (2020). What we can learn from five naturalistic field experiments that failed to shift commuter behaviour. Nature Human Behaviour, 4(2), 169-176.

Le Bon, G. (2007). Crowd psychology. Čačak: Alef.

Mélon, L. (2020). More than a nudge? Arguments and tools for mandating green public procurement in the EU. Sustainability, 12(3), 988.

Nagayama, M. (2005). Organising and reconstructing theories on regional industrial revitalization: Mechanisms of new industry creation in regions. Sinkin-Chukin Monthly Newsletter, October 2005

Oe, H. (2007). Empathy and resonance - Sustainable community network. Tokyo: Japan Institute for Regional Social Research.

Otani, H. (2007) '4 qualitative data analysis method based on step coding SCAT proposal', Nagoya University Graduate School of Education Development of Science Bulletin, 54(2), $27-44$

Parker, S., Hartley, J., Beashel, J. \& Vo, Q. (2021). Leading for public value in multi-agency 
collaboration. Public Policy and Administration, 0952076721999490.

Prensky, M. (2006). Don't bother me, Mom, I'm learning!: How computer and video games are preparing your kids for 21st century success and how you can help!. St. Paul: Paragon house.

Sakamoto, A. (2013). The Japanese approach to research on the psychological effects of media use. In K. E. Dill (Ed.), The Oxford handbook of media psychology (496-510). Oxford University Press.

Sampson, T. D. (2012). Virality: Contagion theory in the age of networks. University of Minesota Press.

Spector, P. E. (2019). Do Not Cross Me: Optimizing the Use of Cross-Sectional Designs. Jounal of Business and Psychology, 34(2), 125-137.

Reijula, S. \& Hertwig, R. (2020). Self-nudging and the citizen choice architect. Behavioural Public Policy, 1-31.

Rogers, E. M. \& Bhowmik, D. K. (1970). Homophily-heterophily: Relational concepts for communication research. Public opinion quarterly, 34(4), 523-538.

Roozen, I., Raedts, M. \& Meijburg, L. (2021). Do verbal and visual nudges influence consuers' choice for sustainable fashion?. Journal of Global Fashion Marketing, 1-16.

Simmering, M. J., Fuller, C.M., Richardson, H. A., Ocal, Y. \& Atinc, G. M. (2015). Marker variable choice, reporting, and interpretation in the detection of common method variance: A review and demonstration. Organizational Research Methods, 18(3), 473-511.

Sunstein, C. R. (2020). Behavioral science and public policy. Cambridge University Press.

Takemoto, T. \& Oe, H. (2021). Entrepreneurship education at universities: challenges and future perspectives on online game implementation. Entrepreneurship Education, 4(1), 1937.

Von Hippel, E. (1994). Sticky information and the locus of problem solving. Management 
Science, 40(4), 429-439.

Williams, L. J. \& McGonagle, A. K. (2016). Four research design and a comprehensive anaysis strategy for investigating common method variance with self-reported measures using latent variable. Journal of Business and Psychology, 31, 339-359.

Wydra, S. (2020). Measuring innovation in the bioeconomy-Conceptual discussion and empirical experiences. Technology in Society, 61, 101242.

Yamaoka, Y. \& Oe, H. (2021a). Examining the effectiveness of the 'Throwing Reach Model' in disseminating information, Journal of Organizational Culture, Communications and Conflict, 25(4) (In press).

Yamaoka, Y. \& Oe, H. (2021b). Business strategies of companies with a longevity of 300 years or longer in Japan: A concept model. International Journal of Management Concepts and Philosophy. (In press) 